Western University

Scholarship@Western

Chemistry Publications

Chemistry Department

8-8-2007

\title{
C-2/c-3 annulation and C-2 alkylation of indoles with 2-alkoxycyclopropanoate esters.
}

Barbora Bajtos

Ming Yu

Hongda Zhao

Brian L Pagenkopf

Follow this and additional works at: https://ir.lib.uwo.ca/chempub

Part of the Chemistry Commons

Citation of this paper:

Bajtos, Barbora; Yu, Ming; Zhao, Hongda; and Pagenkopf, Brian L, "C-2/c-3 annulation and C-2 alkylation of indoles with 2-alkoxycyclopropanoate esters." (2007). Chemistry Publications. 59.

https://ir.lib.uwo.ca/chempub/59 


\title{
C-2/C-3 Annulation and C-2 Alkylation of Indoles with 2-Alkoxycyclopropanoate Esters
}

\author{
Barbora Bajtos, Ming Yu, Hongda Zhao and Brian L. Pagenkop** \\ The University of Western Ontario, Department of Chemistry, London, Ontario, N6A 1Y2, Canada, and The University \\ of Texas at Austin, Department of Chemistry, Austin, Texas, 78712 \\ RECEIVED DATE (automatically inserted by publisher); bpagenko@uwo.ca
}

\begin{abstract}
The annulation reaction between various indoles and 2-alkoxycyclopropanoate esters is reported. Both high efficiency and complete stereochemical control was observed in some cases with this annulation process. A single stereocenter on the cyclopropane controls the diastereoselective formation of up to four new stereocenters. A different reaction course was observed with 3-substituted indole substrates, and an intervening C-3 to C-2migration process arose that gives synthetically useful C-2 alkylation indole products.
\end{abstract}

\section{Introduction}

The ubiquitous nature of the indole nucleus in important bioactive alkaloids fuels research directed at new methods for the synthesis of indoles and their derivatization. Recent examples of indole functionalization include asymmetric C-3 Friedel-Craft reactions, ${ }^{1,2,3}$ allylations, ${ }^{4,5}$ radical couplings, ${ }^{6}$ arylations, ${ }^{7,8,9}$ Michael-additions, ${ }^{10} \mathrm{C}-\mathrm{H}$ activation, ${ }^{11}$ and $\mathrm{N}$-arylations. ${ }^{12}$ Indoles containing a fused 5-membered ring at the $\mathrm{C}-2$ and $\mathrm{C}-3$ positions are well represented in nature, and include the penitrems ${ }^{13}$ and kopsane ${ }^{14}$ alkaloids. ${ }^{15}$ In this regard, it has been reported by Kerr and co-workers that the annulation of indoles with 1,3-dipoles is a successful strategy for rapidly increasing the molecular complexity by simultaneous functionalization of C-2 and C-3, although yields for the annulation products are generally modest. ${ }^{16}$ This was of particular interest to us as we have been developing methods for hetereocycle synthesis based on the annulation of the related family of 2-alkoxycyclopropanoate esters with nitriles, ${ }^{17}$ pyridines ${ }^{18}$ and other reaction partners. ${ }^{19} \mathrm{We}$ envisioned that the more nucleophilic nature of the zwitterionic intermediates from these donor-acceptor cyclopropanes (i.e., an ester versus a malonate) may also undergo annulation with indoles, and in this report we describe our progress in indole annulation and C-2 alkylations.

\section{Results and Discussion}

Reactions with Indoles. Our standard conditions developed for the annulation of nitriles with donor-acceptor cyclopropanes employ polar solvents such as nitromethane combined with a Lewis acid activator, usually a silyl triflate. ${ }^{17}$ When the same conditions were applied to the reaction of indole with cyclopropane $\mathbf{1}$ a clean reaction ensued giving $\mathbf{3}$ as a single diastereomer in $78 \%$ isolated yield (Scheme 1). ${ }^{20}$ The structural assignment of $\mathbf{3}$ was confirmed by single crystal X-ray analysis (Figure 1). $^{21}$
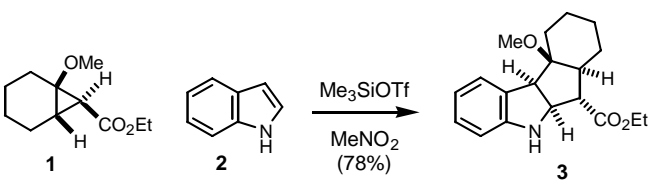

Scheme 1.



Figure 1. X-ray structure of 3.

The reaction scope was then evaluated with indole and additional cyclopropanes offering different substitution patterns (Table 1), including those with the donor oxygen contained within a pyranose (entry 2, 88\%) or furanose ring (entry 3, 58\%), no extra substituents (entry 4,62\%) and one bearing a quaternary carbon at C-2 (entry 5). In entry 2 the annulation resulted in the formation of two inseparable diastereomers, and the stereochemical assignments were made by analysis of the corresponding alcohols prepared by $\mathrm{LiAlH}_{4}$ reduction. 
Table 1. Annulation reactions of indole with representative DAcyclopropanes.
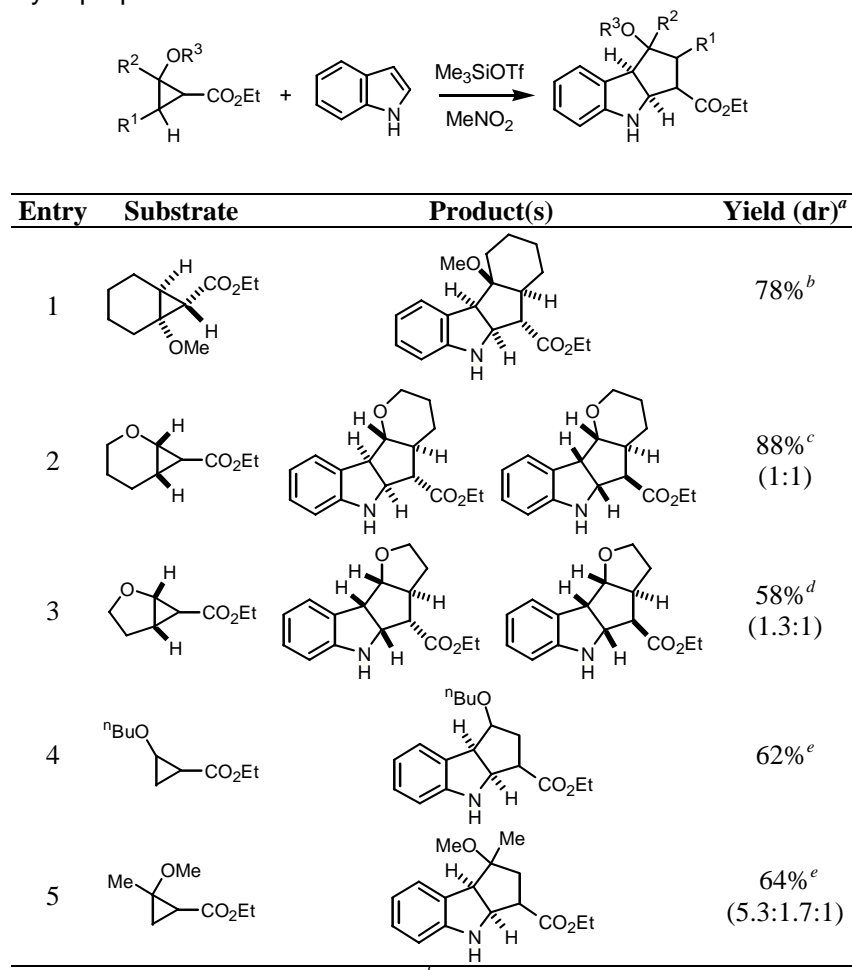

${ }^{a}$ Single diastereomer unless noted. ${ }^{b}$ See ref $21 .{ }^{c}$ Stereochemistry determined by NMR analysis of alcohol derivatives. ${ }^{d}$ Stereochemistry determined by analogy of entry 10 , Table $2 .{ }^{e}$ Stereochemistry not determined.

The scope and generality of this annulation in terms of indole substitution with a variety of representative DA cyclopropanes is summarized in Table 2. These results show that more electron rich 5-methoxy indoles give better yields than 5-iodo indoles (compare entries $1 \& 2,7 \& 8,13 \& 14$ ). However, with three of the cyclopropanes (entries 7 through 14) the methoxyindoles displayed poorer stereoselectivity, whereas the other examples gave single diastereomers. The reaction efficiency with $N$-methyl indole is comparable to the yields obtained within the set for each unique cyclopropane (entries 3 and 11). Substrates methylated at C-5 (entries 4 and 15), C-7 (entries 5 and 16) and C-2 \& C-3 (entry 18) all gave favorable results.

In the examples in Table 2 the only indole-containing products isolated were those resulting from annulation at C-2 / C-3. In contrast, the use of 3-methyl indole was found to give the $\mathrm{C}$-2 alkylation product 5 (Scheme 2), presumably arising from migration of a C-3 alkylation intermediate followed by dehydration. ${ }^{16}$ Intramolecular cyclization of $\mathbf{5}$ gave the lactam $\mathbf{6}$, the structure of which was confirmed by single crystal $x$-ray crystallography. ${ }^{21}$
Table 2. Scope of annulations of substituted indoles with DA cyclopropanes

Entry Cyclopropane Indoles: R, R'

${ }^{a}$ Single diastereomer isolated unless noted. ${ }^{b}$ Stereochemistry determined by analogy to entry 1 , Table $1 .{ }^{C}$ Reaction performed at $-18{ }^{\circ} \mathrm{C}$. ${ }^{d}$ Stereochemistry determined by NMR analysis. ${ }^{e}$ Reaction performed at $0{ }^{\circ} \mathrm{C}$. ${ }^{f}$ See Table 1 for relative stereochemistry of other diastereomer. ${ }^{g}$ See ref $21 .{ }^{h}$ See ref $22 .{ }^{i}$ See ref $23 .{ }^{j}$ Stereochemistry not established.

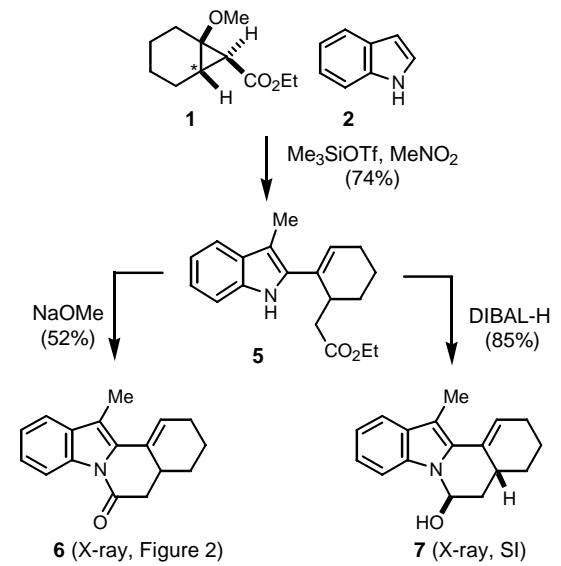

Scheme 2. Migration and amide/aminal formation. 


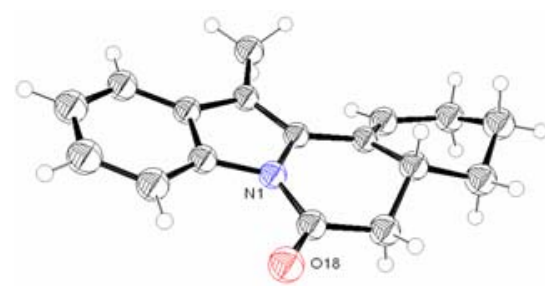

Figure 2. X-ray structure of 6.

The additional five examples summarized in Table 3 present C-3 substituted indoles that highlight the compatibility of the method with additional functional groups offering greater synthetic potential. In entry 2, a 3-allyl substituent is introduced, and the C-2 alkylation product was obtained in $74 \%$ yield. Examples 3 through 6 illustrate indoles with C-3 side chains bearing hetereoatoms. Specifically, entries 3 and 4 show that 3( $N$-acyl-2-aminoethyl) and 3-(methoxycarbonylethyl) side chains are good reaction partners, giving the $\mathrm{C}-2$ alkylated indoles in $60 \%$ and $72 \%$ yield, respectively. In entry 5 a 3-(2hydroxyethyl) size chain gives the alkylation product in $50 \%$ yield, and this was improved to $63 \%$ (entry 6) by acylation of the alcohol.

Table 3. C-2 Alkylation of C-3 substituted indoles by DA cyclopropane 1.

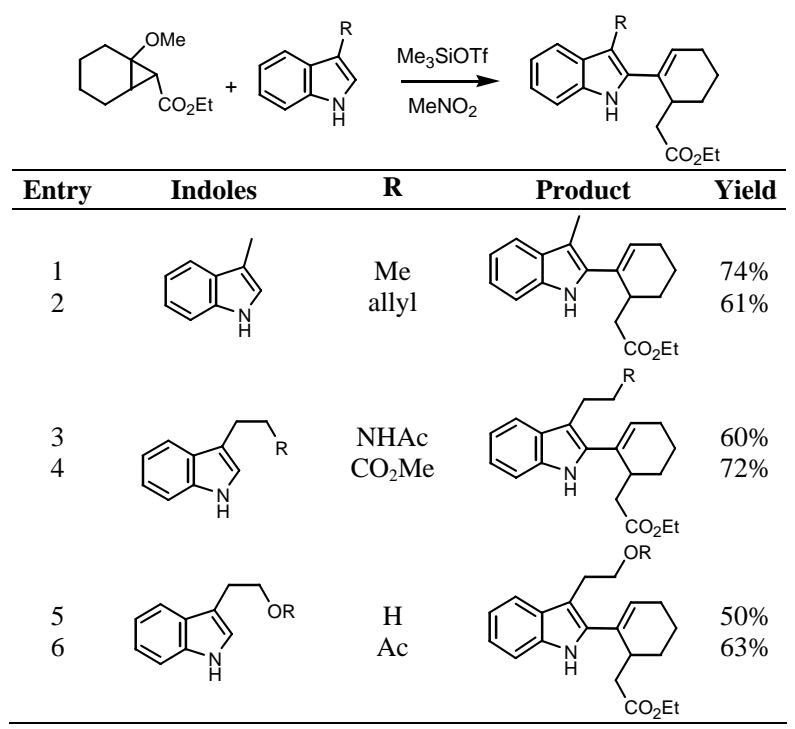

Origin of Stereochemistry and Stereochemical Assignments. Regarding the stereochemistry of these annulation products it is important to note that for three of the five classes of cyclopropanes summarized in Tables 1 and 2, a representative crystal structure has been obtained to unambiguously assign the stereochemistry shown (c.f., Table 2 entries $1-5$, Figure 1; entries 7 - 8, Figure 3; entries $10-12$, Figure 4). Note that Figure 4 clearly shows the strained 5,5-trans ring fusion. For these entries and several of the others the stereochemistry was confirmed or established by extensive NMR analysis (Figure 5), whereas in other cases stereochemistry was assigned on the basis of analogy or left unassigned. These annulation reactions occur within a narrow temperature range, and in one case (entry 6, Table 2) complete diastereoselectivity was observed at low temperature $\left(-18{ }^{\circ} \mathrm{C}\right)$ whereas there was a loss of selectivity at increased temperature $\left(0^{\circ} \mathrm{C}\right)$. It is also noteworthy that entries 6 and 9 in Table 2 have different relative stereochemistry compared to the other entries within their cyclopropane class (entries 1-5,
Table 2; entries 7-8, Table 2; respectively) due to the unfavorable 1,2-eclipsing interaction between the C2-methyl and the ester substituent.

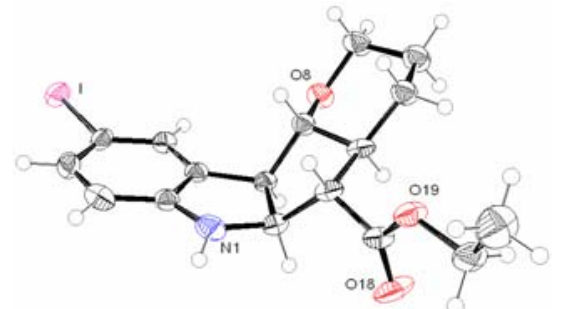

Figure 3. X-ray structure of entry 8, Table 2.

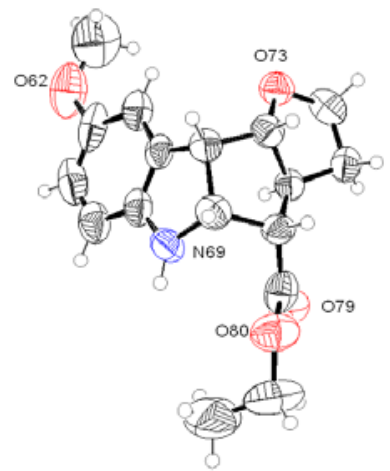

Figure 4. X-ray structure of entry 10, Table 2, showing the trans ring fusion.
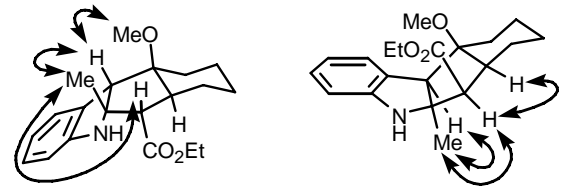

Figure 5. Select NOE data for diastereomers from entry 6, Table 2.

From these X-ray structures (Figures 1, 3 and 4) and the supporting NOESY information it can be seen that attack on the oxo-carbenium ion intermediate from the indole $\mathrm{Re}$ or $\mathrm{Si}$ face occurred anti to the ester substituent (Scheme 3). Thus, one of the non-enolizable stereocenters in the original cyclopropane (identified with an asterisk) is responsible for controlling the relative stereochemistry of up to four new stereocenters formed in this reaction.

Relative energies of four possible diastereomers in three cyclopropane classes (entry 2, Table 1; entries 6 and 10, Table 2) were calculated using Semi-Empirical(SE)/PM3 and HartreeFock(HF)/3-21G methods. The most stable energy isomers were the observed annulation products in all cases. ${ }^{24}$ 


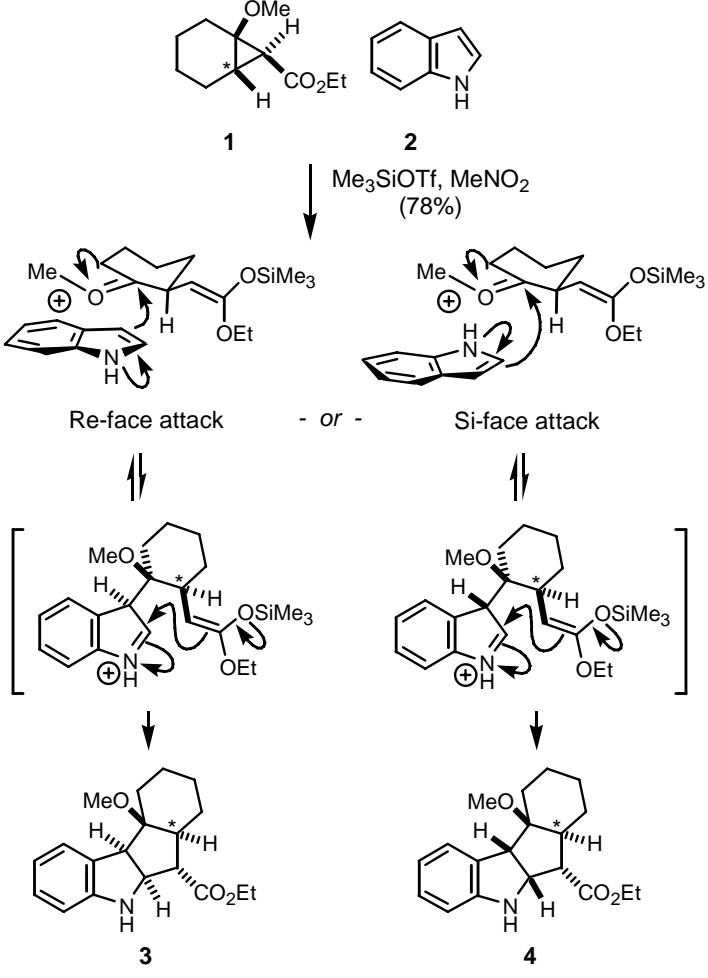

Scheme 3. Origin of Stereochemical Control.

\section{Conclusion}

The annulation reaction between various indoles and 2alkoxycyclopropanoate esters is reported. Both high efficiency and complete stereochemical control was observed in many cases with this annulation process. A different reaction course was encountered with 3-substituted indole substrates, and an intervening $\mathrm{C}-3$ to $\mathrm{C}$-2-migration process arose that gives synthetically useful C-2 alkylated indoles.

Acknowledgement. This work was supported in part by NSERC, Johnson and Johnson, and donors of the American Chemical Society Petroleum Research fund. We thank Drs. Vincent Lynch and Michael Jennings for determination of the Xray structures.

Supporting Information Available: Experimental procedures and characterization of all new compounds, CIF files, selected NOESY and gCOSY data, and SE/PM3 and HF/3-21G energy information. This material is available free of charge via Internet at http://pubs.acs.org.

\section{References}

(1) Wang, Y.-Q.; Song, J.; Hong, R.; Li, H.; Deng, L. J. Am. Chem. Soc. 2006, 128, 8156-8157.

(2) Palomo, C.; Oiarbide, M.; Kardak, B. G.; Garcia, J. M.; Linden, A. J. Am. Chem. Soc. 2005, 127, 4154-4155.

(3) Evans, D. A.; Scheidt, K. A.; Fandrick, K. R.; Lam, H. W.; Wu, J. J. Am. Chem. Soc. 2003, 125, 10780-10781.

(4) Trost, B. M.; Quancard, J. J. Am. Chem. Soc. 2006, 28, 6314-6315.

(5) Kimura, M.; Futamata, M.; Mukai, R.; Tamaru, Y. J. Am. Chem. Soc. 2005, 127, 4592-4593

(6) Baran, P. S.; Richter, J. M. J. Am. Chem. Soc. 2004, 126, 7450-7451.

(7) Deprez, N. R.; Kalyani, D.; Krause, A.; Sanford, M. S. J. Am. Chem. Soc. 2006, 128, 4972-4973.

(8) Wang, X.; Lane, B. S.; Sames, D. J. Am. Chem. Soc. 2005, 127, 49964997.

(9) Bressy, C.; Alberico, D.; Lautens, M. J. Am. Chem. Soc. 2005, 127 13148-13149.

(10) Zhou, J.; Tang, Y. J. Am. Chem. Soc. 2002, 124, 9030-9031.
(11) Davies, H. M. L.; Manning, J. R. J. Am. Chem. Soc. 2006, 128, 10601061.

(12) Antilla, J. C.; Klapars, A.; Buchwald, S. L. J. Am. Chem. Soc. 2002 124, 11684-11688.

(13) Naik, J. T.; Mantle, P. G., Sheppard, R. N.; Waight, E. S. J. Chem. Soc. Perkin Trans. I 1995, 1121-1125.

(14) Achenbach, H.; Biemann, K. J, Am. Chem. Soc. 1965, 87, 4944-4950.

(15) (a) Cheng, K. F.; Cheung, M. K. J. Chem. Soc. Perkin Trans. I 1996 1213-1218. (b) Magnus, P.; Gallagher, T.; Brown, P.; Huffman, C. J. Am. Chem. Soc. 1984, 106, 2105-2114. (c) Kuehne, M. E.; Seaton, P. J. J. Org. Chem. 1985, 50, 4790-4796.

(16) (a) England, D. B.; Woo, T. K.; Kerr, M. A. Can. J. Chem. 2002, 80, 992-998. (b) England, D. B.; Kuss, T. D. O.; Keddy, R. G.; Kerr, M. A. J. Org. Chem. 2001, 66, 4704-4709.

(17) Yu, M.; Pagenkopf, B. L. J. Am. Chem. Soc. 2003, 125, 8122-8123

(18) Morra, N. A.; Morales, C. L.; Bajtos, B.; Wang, X.; Jang, H.; Wang, J.; Yu, M.; Pagenkopf, B. L. Adv. Syn. Cat. 2006, 2385-2390.

(19) (a) Yu, M.; Pagenkopf, B. L. Tetrahedron 2005, 61, 321-347. (b) Gnad, F.; Reiser, O. Chem. Rev. 2003, 103, 1603-1624. (c) Reissig, H. Y.; Zimmer, R. Chem. Rev. 2003, 103, 1151-1196.

(20) Identical results (efficiency and stereoselectivity) were obtained from either diastereotopic cyclopropane or mixtures. For the other experiments described in this manuscript mixtures of diastereomers were employed.

(21) Structural assignment of the following compounds was confirmed by single crystal x-ray crystallography: 3 (Table 1 , entry 1 ), 6, 7, Table 2 (entry 8 and 10, where entry 10 has additional NMR analysis). See Supporting Information for additional stereochemical proofs.

(22) The structural assignment of entry 9 , Table 2 was set by analogy to entry $6 \mathrm{~b}$, Table 2, that is consistent with the most stable energy product. All energy values and calculations are in the Supporting Information.

(23) The structural assignments of entries 11 and 12, Table 2 were assigned on the basis of analogy for the major diastereomer determined by NMR analysis and single crystal X-ray of entry 10 , Table 2 and its relative alcohol derivatives.

(24) All energy values and calculations are in the Supporting Information. 


\section{C-2/C-3 Annulation and C-2 Alkylation of Indoles with 2-Alkoxycyclopropanoate Esters}



Barbora Bajtos, Ming Yu, Hongda Zhao and Brian L. Pagenkopf*

ABSTRACT FOR WEB PUBLICATION: The annulation reaction between various indoles and 2-alkoxycyclopropanoate esters is reported. Both high efficiency and complete stereochemical control was observed in some cases with this annulation process. A single stereocenter on the cyclopropane controls the diastereoselective formation of up to four new stereocenters. A different reaction course was observed with 3-substituted indole substrates, and an intervening C-3 to C-2-migration process arose that gives synthetically useful C-2 alkylation indole products. 